\title{
Public Private Partnerships in food industries: A road to success?
}

\author{
Elodie Rouvière ${ }^{\mathrm{a}, \Uparrow}$, Annie Royer ${ }^{\mathrm{b}}$ \\ a AgroParisTech, UMR-G-EAU, 648 rue Jean François Breton, F-34093 Montpellier, France \\ ${ }^{\mathrm{b}}$ Laval University, Dept. of Agricultural Economics and Consumer Science, 2425 rue de l'Agriculture, G1V 0A6, Canada
}

\section{Introduction}

Increases in the number of food-borne diseases ${ }^{1}$ along with the steadily occurrence of high-profile outbreaks linked to food in various industrialized countries have created both political and economic demands for more effective and costly food safety controls. Given the costs of these controls, governments tend to give food operators more responsibility in handling and preventing food safety hazards (Verbruggen and Havinga, 2015a,b). Indeed, many countries have promulgated laws that encourage the food industry to implement voluntary food safety hazard control plans and make preventive efforts to minimize the probability of a food safety hazard occurrence. Besides, we also observe the emergence of new collaborations between public authorities and food operators in monitoring food safety (Cafaggi, 2010; Garcia-Martinez et al., 2007).

The literature is replete with analysis of collaborations between public authorities and firms in all economic activities (see Black, 2001). However, this literature, depending on the discipline (economics, sociology, political science) uses multiple concepts - albeit blurred - to name these collaborations: co-regulation, enforced self-regulation, meta-regulation, hybrid regulation and so on. This abundance of terms led to a fuzzy understanding of these collabo-

\footnotetext{
$\Uparrow$ Corresponding author.

E-mail addresses: elodie.rouviere@agroparistech.fr (E. Rouvière), annie.royer@eac.ulaval.ca (A. Royer)

1 Tauxe (1997) and Newell et al. (2010).
}

rations depending on the analyses' focus: their emergence (Mayer and Gereffi, 2010; Coglianese and Mendelson, 2010), the risks of regulatory capture and loss of transparency (Verbruggen and Havinga, 2014), etc. As suggested by Verbruggen and Havinga (2015a,b), one common feature of this literature is that these collaborations are an output of the regulatory/political process (standard-setting, implementation, enforcement and monitoring) and appear as a mean to comply with a regulatory standard. In other words, co-regulation is a regulatory tool for food operators' compliance.

More specific to food safety issues, the literature has mostly dealt with the effects of private systems on the organization of transactions in the global supply chain (Busch and Bain, 2004; Cafaggi, 2010) or attempt to qualify public and/or private agents' incentives to participate in such system (Garcia-Martinez et al., 2007; Rouvière et al., 2010). Recent contributions consider these partnerships as public and private actors working side-by-side to deliver (co-) regulatory outputs. Garcia-Martinez et al. (2013) provide a framework that distinguishes forms of collaborations according to the stages of the regulatory process from which they emerge (Garcia-Martinez et al., 2007, 2013). They distinguish two broad co-regulation models, in which either private agents (bottom-up models) or public agents (top-down models) control or monitor the other. These models have undeniably improved our understanding of these organisations. However, GarciaMartinez et al. (2013) suggest the need for scholars to deepl 
research such organisations so as to better understand their structure and their functioning.

In this article, we shed new light on these collaborations. We explore them from a different perspective that puts uncertainty and specific food safety concerns, such as systemic risks (collective dimension) and information asymmetry (credence attribute of food safety), as the main criteria of their functioning. To do so, we first consider them as embedded (meso) institutions, as suggested by Ménard (2014), looking at them as Public Private Partnership (PPP) specific to food safety and traceability. This perspective allows us to (i) consider these arrangements as newly created meso-institutions, merging both public and private actors in a single institutional frame in response to food safety incidents, rather than having public and private actors work side-by-side to deliver (co-) regulatory outputs, (ii) identify general incentive mechanisms that contribute to their resilience. In other words, we borrow concepts from the literature on meso-institutions and on PPP that we adapt to the food safety and traceability context. We intend to provide an enriched theoretical framework to discuss how the structure of these singular partnerships might help achieve the shared goals of food safety and traceability. Our general framework is then applied to two specific case studies to highlight the mechanisms at work that would explain their functioning and resilience: the cattle traceability system in Quebec (Canada) and monitoring programmes for pesticide residues in the French imports industry of fresh produce.

This article proceeds as follows: In Section 2, we provide an overview of the prevalence of these collaborative arrangements in the food industry as well as how scholars have analyzed them so far. In Section 3, we build our analytical framework. In Section 4, we use this framework to show how two PPPs, respectively from Canada and France, are organised and what are the mechanisms at work that would explain their resilience. Section 5 concludes.

\section{Public private coordination in the food industry}

\subsection{Context}

Food-born diseases outbreaks are costly, both in terms of lives and money. The outbreak of listeriosis in cantaloupes in the United States ${ }^{2}$ in 2011 killed 30 people while cantaloupes' prices underwent a dramatic reduction. The mad cow crisis in Canada translated in losses close to $\$ 11$ millions a day in exports due to closed borders and $\$ 7$ millions a day because of drop in prices (Forge and Fréchette, 2005). In 2012, in France, Escherichia coli O 157:H7 was found in minced beef meat sold by Carrefour after three children have been contaminated. ${ }^{3}$ In early 2009, Peanut Corporations of America, which is now bankrupt, prompted a recall of 3918 related peanut butter products after nine people died, and 22,500 more people were sickened. ${ }^{4}$

In response to recent food/traceability scares, prevention has become one of the primary food safety tool. In most developed countries, food safety regulations require all food processors, manufacturers, packers and handlers to identify and implement preventive efforts to minimize the probability of safety hazards to occur. In Europe, the General Food Law ${ }^{5}$ was promulgated in 2002

\footnotetext{
${ }^{2}$ http://www.cdc.gov/listeria/outbreaks/cantaloupes-jensen-farms/120811/ (February 2015).

${ }^{3}$ http://www.lemonde.fr/economie/article/2012/10/17/retrait-et-rappel-desteaks-haches-commercialises-chez-carrefour-et-champion_1776768_3234.html (February 2015).

${ }^{4}$ http://www.fda.gov/Safety/Recalls/ArchiveRecalls/2009/ucm128828.htm (March 2015).

${ }^{5}$ Regulation (EC) No 178/2002 of the European Parliament and of the Council of 28 January 2002 laying down the general principles and requirements of food law, establishing the European Food Safety Authority and laying down procedures in matters of food safety.
}

and has been enforced since 2005. The Law highlights the need for food operators to develop food safety hazard control plans and to better monitor the safety of their inputs and outputs. In other words, European food operators have been encouraged to implement safety efforts on their operations. The same trend appears in the United States, with the 2010 FDA Food Safety Modernization Act (FSMA) that amends the 1938 Food, Drug, and Cosmetic Act. The Act requires all food operators in the food supply chain to identify and implement preventive effort to minimize the probability of a safety hazards to occur (Pouliot, 2011). In the UK, the 1990 Food Safety Act encouraged supermarkets to institute themselves effective internal procedures to ensure that control mechanisms had indeed been introduced in the sector (Hobbs and Kerr, 1992). In Canada, the Canadian Food Inspection Agency (CFIA) established in 1997 is responsible for enforcing Canadian food safety laws through slaughterhouses/processing firms' inspections and product analysis. In the 2012 federal budget, the Canadian government agreed to reduce costs by giving more responsibility to the food industry (food producers, processors and importers) to police its own safety practices, develop and implement their own risk-control systems (CFIA, 2014).

In parallel with this public response, we have seen the emergence of new management systems with increased collaboration between public and private agents. Garcia-Martinez et al. (2013) reviewed collaborative programmes for food safety in the United Kingdom and the Netherlands. Garcia-Martinez et al. (2007) provided examples of public-private coordination in the United States, Canada and the United Kingdom. This review of experiences demonstrated that coordination may take various forms such as HACCP programmes, quality schemes and codes of good practices that would be used at various regulatory stages to improve efficacy and/or economic efficiency of food safety controls.

All over the world, we find a plethora of those safety and traceability schemes. In the United Kingdom, the Red Tractor label is a food insurance scheme covering production standards on safety, hygiene, animal welfare and the environment, and accredited by the United Kingdom Accreditation Service (McEachern and Warnaby, 2004). This insurance scheme paid by producers and food companies is operated by an independent organization. The Red Tractor label appears on fresh produce (meat, dairy, fruit, vegetables and salads). It means the product is "traceable, safe to eat and has been produced responsibly from farm to fork". 6 In the Netherlands, "RiskPlaza" was set up on the initiative of a bakery chain but is now applied to all food sectors. "RiskPlaza" is a metacontrol system that assesses and monitors the functioning of these private systems (Verbruggen and Havinga, 2014, 2015a,b). It is a database that gives information about food safety hazards, which may be associated with ingredients and how to manage these hazards. The new Dutch Food and Consumer Product Safety Authority (nVWA) is involved at various levels of RiskPlaza (expertise, regulation, harmonisation). In the United States, the California Leafy Green Products Handler Marketing Agreement ${ }^{7}$ (LGMA) was initiated in the spring 2007 in response to the September 2006 E. coli outbreak that was attributed to spinach grown in California. Tomato Producers in Florida and leafy green producers in Arizona $^{8}$ have implemented similar programmes. Leafy green and tomato producers also began these mandatory programmes in 2007. The California cantaloupe ${ }^{9}$ mandatory safety program was launched in 2012. It was initiated by growers and handlers and is approved by public authorities as well as certified by mandatory government inspections. Recent contributions have also mentioned the presence of these collaborative arrangements in developing a sustainable seafood industry while

\footnotetext{
${ }^{6}$ http://www.redtractor.org.uk/about-us (April 2015).

http://www.lgma.ca.gov (February 2015).

http://www.arizonaleafygreens.org/ (May 2014).

${ }^{9}$ http://www.californiacantaloupes.com/food-safety (May 2014).
} 
they have not been linked to food safety (Oosterveer, 2015). In the context of developing countries, Narrod et al. (2009) argue that public-private partnerships can play a key role in creating linkages to satisfy market demands for food safety, while retaining smallholders in the supply chain. In 2012, Kersting and Wollni show that PublicPrivate Partnerships support the implementation of new institutional arrangements in the Thai fresh fruit and vegetable supply chain.

\subsection{From co-regulation...}

In the food safety literature, scholars mostly consider these arrangements as the result of a regulatory change (GarciaMartinez et al., 2007; Rouvière and Caswell, 2012; Verbruggen and Havinga, 2014). In this perspective, these programmes are implemented as regulatory tools in order to enforce newly designed food safety standards or traceability systems (GarciaMartinez et al., 2007, 2013; Rouvière and Caswell, 2012). The newly developed systems are considered as private strategies to regulatory changes. These schemes would help food operators to comply with new regulations.

A recent paper differentiates these newly developed systems based on the phase in which they were established during the regulatory process. Garcia-Martinez et al. (2013) have conceptualized collaborative system models in a dichotomic approach, considering the interaction between public and private agents to explain and differentiate among the variety of collaborative arrangements. They summarize the literature on self-regulation and its links to the wide definition of regulation in regard to government intervention in the market (Posner, 1973). Regulations are considered as institutions or the rules of the game, as defined by North (1994). There is a consensus that the collaboration between public and private agents is located somewhere in-between command and control intervention, and self-regulation (Garcia-Martinez et al., 2007; Ogus, 2000; Rouvière and Caswell, 2012). Moreover, Garcia-Martinez et al. (2013) underline that collaborative arrangements can be established at different phases of the regulatory process. They therefore differentiate models among four stages: (i) regulatory standard-setting process, (ii) process implementation, (iii) enforcement and (iv) monitoring.

From this perspective, Garcia-Martinez et al. (2013) identified two broad models of co-regulation: Top-Down models or "enforced self-regulation" and Bottom-Up models or "recognized industry-level regulation". They highlight that Top-Down and Bottom-Up models differ in the level of public mandate given to the private sector to implement public policies objectives. They also differ in their position within the regulatory process. TopDown models are defined on standard setting and implementation activities whereas Bottom-Up models are defined on monitoring and enforcement activities. In this view, self-regulation and command-and-control forms of regulation are perceived as polar arrangements. Bottom-up models refer to the recognition of private actions at the industry level. However, public agents are not in charge of monitoring, which means that the private scheme doesn't automatically lead to compliance with the public legal framework. In other words, Bottom-up models constitute a category of self-regulation models with a regulatory approval but that do not satisfy public standard compliance objectives. In Top-Down models, public authorities approve and enforce private agents' initiatives related to compliance to food safety standards. Public authorities ratify self-enforcement and are still in charge of monitoring compliance. The main characteristics of such models are flexibility for firms and oversight at the firm level. We can argue from this analytical framework that this type of arrangements is based on the decision of public agents to approve and enforce firms' commitments, confirming that these two models are regulatory tools.

Our approach is original since all the articles that explore the public-private collaborations in the food safety governance make the stages of the regulatory and the political process as one of the main determinants of the structure and the organization of this collaboration (Verbruggen and Havinga, 2015a,b). Here, we adopt another perspective, analysing these collaborations as mesoinstitutions as defined by Ménard (2014), and thus, considering them as free from the influence of the regulatory process. This allows us to consider these arrangements merging both public and private actors in a single institutional frame in response to food safety incidents and to identify the mechanisms at work that could lead to their functioning and their resilience.

\section{3. ...To Public Private Partnerships}

Recent researches have focused on understanding hybrid institutions mixing private and public entities. Thus, new concepts such as meta-controls in the Dutch food industry (see Verbruggen and Havinga, 2015a,b) or meta-governance (see van der Voort, 2015) have emerged. In a recent article, Ménard (2014) studies the innovative organizational arrangements between institutions (as rules of game) and organizational arrangements (players), calling them meso-institutions. He defines meso-institutions as devices that implement "the general rules of the game through their translation into rules specific guidelines for individuals as well as organizational arrangements that are operating within this frame". Ménard (2014) suggests a framework that identifies and analyses the specific mechanisms of these innovative arrangements. Meso-institutions might transform the general rules (institutions) into specific ones adapted to the specific technical characteristics of the system they frame and monitor, thus providing guidelines to actors and making rules enforceable. As suggested by Menard's framework, these collaborations can thus be seen as an adaptive strategy from both public and private agents to a non-manageable exogenous shock rather than the result of a regulatory change.

Royer et al. (2016) apply this framework to the agri-food industry in order to explain the resilience of marketing boards in Canada, interprofessions in France and marketing orders in the United States. They provide insights on how these arrangements can outperform 'command and control' regulation and pure market mechanisms. Royer et al. (2016) argue that their organizational and institutional properties, as meso-institutions, translate into incentive mechanisms that solve coordination problems. Indeed, food products require a tight coordination because of the interdependence of actors and their perishable nature. Royer et al. (2016) provide the main characteristics of these arrangements: they must be collective, and thus provide incentive mechanisms to avoid free riding, so as to reduce transactional uncertainty.

In this article, we combine these two approaches considering these public-private coordination schemes as one type of mesoinstitutions: Public Private Partnerships for food safety and traceability. While the most studied public-private partnerships are those used in infrastructures development, many other types of public-private partnerships exist (Boase, 2000). We thus analyse a shared contract between public authorities and private food firms that take into account the specificities of food industries and their uncertainties.

\section{PPP for food safety and traceability: an analytical framework}

In the food industry, public-private collaborations usually emerge after a crisis or an outbreak that underlines private and public failures in the previous system (see Section 2). In this sec- 
tion, we first reconsider uncertainties related to food safety and traceability systems. We then suggest a way for the PPPs literature to take into account food safety and traceability specificities.

\subsection{Food safety and traceability uncertainties}

In the economic literature, food safety is mostly considered as a credence attribute of food items: high transaction costs prevent consumers from checking the real nature of products even after consumption (Barzel, 1982). Consumers therefore need guarantees on the safety of food items they eat. This market failure is due to the asymmetric information on food safety attributes between producers and customers/consumers (Antle, 1996).

Raw products may have different safety levels and consumers consider some food products as generic (unbranded product). When buying their food products (fresh produce), consumers make their decisions based on the reputation of the entire food industry or sector. In that sense, food operators share the reputation of the industry (Rouvière and Soubeyran, 2011). Consequently, following a food poisoning outbreak, all stakeholders along the contaminated product supply chain may suffer the consequences of a decrease in demand. This problem arises because consumers cannot link the contamination to a particular producer. As noted, food supply is systemic by nature (Hennessy et al., 2003). However, it is worth noting that although it is difficult to identify the culprit during the crisis, it is becoming easier to identify ex-post the firm responsible for the outbreak with the new techniques available.

There also exist situations where food products are not traceable by consumers who are not able to identify either the producer or the level of safety of a food item. Golan et al. (2004) define traceability as "recordkeeping systems designed to track the flow of products or product attributes through the production process or supply chain" (p.1). Traceability systems have been developed in order to address information asymmetries arising from food safety and food quality attributes (Hobbs, 2004).

Information asymmetry existing between food operators and consumers is also present in Business-to-Business relationships within chains. Distributors, processors and producers do not know how products are produced or handled in each other's hands. Traceability systems can be designed to control animal diseases, differentiate products, isolate losses from a food safety or product quality problem, protect the reputation of a product, a firm, an industry or a country, and to comply with importing countries requirements. Industry-wide traceability systems facilitate trace back for food safety and reduce recall expenses for a whole industry or sector. They mainly display ex post traceability functions that are aiming at limiting the extent of food safety outbreaks and in maintaining consumer confidence in an industry (Hobbs, 2004). Traceability systems might be considered as new technologies implemented by food operators in order to reduce uncertainty in transactions and allocate responsibilities.

Information asymmetry, the systemic nature of risk due to credence attributes and public goods/services nature of food goods all lead to market failures and uncertainties in transactions in the whole supply chain. As suggested by Royer et al. (2016) these uncertainties lead to the need of a tight coordination through industry-wide actions.

\subsection{Which PPPs for food safety and traceability?}

The use of PPPs to frame the provision of public goods/services is widespread worldwide. PPPs are viewed as a solution to reduce governments costs and improve private incentives. PPPs are generally understood as contractual arrangements between one sole private firm and a public entity to provide a public service or good. However, there are many other types of PPPs. Boase (2000) pro- vides a full typology of PPPs. Boase (2000) identifies four types of PPPs that differ as per their level of power-sharing or influence on decision-making between public and private agents. Boase (2000) do not refer to the stage of a regulatory process. However, Boase (2000) underlines that few PPPs strictly conform to those ideal types. From his definition, we can easily spot those PPPs in our framework and give examples on arrangements that exist in the food industry. Using the PPP framework, we can remove the regulatory process component.

A first type of PPP refers to consultative arrangements where governments seek an expert input from a group or an organization of the society. These consultative arrangements are not part of regulatory programmes since they are not focused on complying with public standards. But they aim to help governments and firms to implement new programmes. For instance, in the agrifood system, the roundtable on sustainable palm aims to transform markets to make sustainable palm oil the norm. ${ }^{10}$

A second type is contributory partnerships where a public organization funds a societal organization to carry out an activity over which the sponsor has little control. The Safe Supply of Affordable Food Everywhere (SSAFFE) initiative is a good example of contributory partnerships in the food industry. SSAFFE is a partnership between international food companies, NGOs, intergovernmental organisations and research. ${ }^{11}$ They provide a low level of public involvement and influence and they are out of the scope of regulatory goals.

A third type refers to operational or community development partnerships where a particular group and the government work together to achieve compatible or common goals. The emphasis in these types of arrangements is on joint contributions for the achievement of mutual goals. This PPP aims to reduce information asymmetry between partners, leading to lower transaction costs in the implementation and operation of the PPP, such as information gathering, enforcement and monitoring costs compared to pure public or pure private regulation arrangements.

Finally, a fourth type of PPP is called collaborative partnership. Under such partnerships, which will be referred to as contractual PPPs from now on, a local authority or a central-government agency enters a long-term contractual arrangement with one private supplier for the provision of infrastructure projects and/or public services (water services for instance). They imply a very important phase of negotiations. There is a wide literature on the drivers, impacts and performance of contractual PPPs (de Bettignies and Ross, 2004; Hodge and Greve, 2007; Iossa and Martimort, 2015).

The most noticeable difference between an operational and a contractual PPP is that the former does not involve a contractingout relationship as such and the latter does not consider the industry-wide dimension. Contractual PPPs are highly subject to so-called contractual hazards due to asymmetric information and non-observability of effort that may lead to high transaction costs. Individual partners must undertake relationship-specific investments that may generate ex post inefficiencies such as ex post bargaining to appropriate the quasi-rent and ex ante inefficiencies such as ex post incentive problems over assets due to a misallocation of initial property rights.

In operational PPPs, the relationship between public and private agents doesn't rest upon physical investments but on a relation, that involves not only one firm but many. This raises a freeriding issue as food operators are profitmaking firms that might want to try to reap the benefits of the collaboration without supporting their part of the cost. The other component of contractual

\footnotetext{
${ }^{10}$ http://www.rspo.org/ (March 2015).

11 http://www.ssafe-food.org/index.php/projects (March 2015).
} 
PPPs that differentiates them from operational ones is the financing capacity. The private sector involved in an operational PPP does not necessarily provide an important financing capacity, as physical investments are not that much important.

From Boase's typology (2000), we argue that PPPs used in the food safety and traceability contexts are hybrids between contributory and contractual PPPs. They can be used to provide public services, to escape from the regulatory process that rather focuses on regulatory instrument to imply compliance strategies.

\subsection{Industry wide PPPs for food safety and traceability}

Boase (2000) highlights core mechanisms of contributory and contractual PPPs that will constitute our framework. We then use this framework to highlight mechanisms at work in our cases studies.

Boase (2000) argues that operational PPPs lower transaction costs such as information search, enforcement and monitoring costs. Moreover, Royer et al. (2016) argue that these collective arrangements must provide mechanisms to avoid free riding and reduce uncertainties surrounding transactions such as in contractual PPPs. We thus focus on such incentives mechanism that can help lower transaction costs (see Table 1).

First of all, those partnerships imply an alignment of public and private incentives. In other words, they share mutual goals and can then be considered in a single frame. The involvement of the private sector in a partnership with the public sector would allow greater economies of scale and access to higher-powered incentives than the public sector alone (de Bettignies and Ross, 2004). In an operational partnership, the issue of alignment is particularly at stake since heterogeneity between firms can influence their individual effort (Rouvière, 2016). Partners involved in PPPs are under mutual dependency and are both empowered in the partnership. They share responsibilities, costs and their know-how. In other words, they share risks. While enforcement and oversight are key components, the issue of reliability is much more important in operational PPP between one public authority and multiple heterogeneous firms. Reliability refers to the notions of trust and the capacity to self-report which makes the system reliable. A clear accountability for failures needs to be designed by these arrangements. In our context, accountability refers to the allocation of liability in case of safety/traceability failure.

Secondly, partnerships allow having a better access to private information. For instance, in the case of food safety, private partners have more information than their counterpart of the public sector concerning the difficulties of implementing and monitoring rules. This informational advantage can be used within a PPP to reduce information search cost and improve food safety rules implementation success. Sinclair (1997) mentions that the expertise of the private actors, their technical know-how, can enhance the results of the measures by adapting them to their reality.

Thirdly, better-adapted measures may reduce compliance costs, speed up the process implementation and enhance enforcement and monitoring, thus reducing costs. That way, PPPs could also be a way to encourage compliance rather than incurring significant enforcement costs or risk system failure through pervasive noncompliance (Hobbs et al., 2007). Therefore, PPPs may become a particularly desirable alternative for the provision of public services that do not necessitate physical investments. Table 1 summarizes the main characteristics of PPPs found in a food safety context.

\section{Case studies in France and Canada}

In this section, we provide two PPP case studies in France and Canada. Garcia-Martinez et al. (2013) and Ménard (2014) argue
Table 1

Characteristics of a PPP framing food safety.

\begin{tabular}{cll}
$\begin{array}{l}\text { Incentives' } \\
\text { alignment }\end{array}$ & Information & Enforcement \\
\hline $\begin{array}{l}\text { Shared goals } \\
\text { Shared risks }\end{array}$ & $\begin{array}{l}\text { Private information } \\
\text { disclosure }\end{array}$ & $\begin{array}{l}\text { Industry's incentive } \\
\text { tools }\end{array}$ \\
$\begin{array}{c}\text { Reliability } \\
\text { Accountability }\end{array}$ & $\begin{array}{c}\text { Available record-keeping } \\
\text { system }\end{array}$ & \\
\hline
\end{tabular}

that the institutional environment matters when dealing with these hybrid arrangements. For Ménard (2014), meso-institutions can differ from one country to another while having the same objective.

We argue that PPP for food safety and traceability can have general features that are not linked to the environment in which they are implemented. To address this claim, we use our newly developed framework on two case studies. Our framework allows us to highlight the main mechanisms at work that can contribute to the functioning and the resilience of two specific programmes.

\subsection{The rationale for PPP in France and Canada}

One of the cases concerns the implementation and management of an industry-wide traceability system for cattle in Québec, Canada. The partnership basically consists of the Quebec government, the main producers' union and an autonomous non-profit organization. The other case takes place in France with an approved program in the imports industry of fresh produce. The partnership includes importers, traders and exporters on the two main French import markets of fresh fruit and vegetables and the French administrative agency in charge of monitoring food safety to consumers (DGCCRF). These two cases are both industry-wide schemes that fit in our newly given definition of Public-Private Partnership for food safety and traceability. We have shown in the above sections that food safety and traceability are public services and show different potential market failures that involve public and private agents. These characteristics sustain the implementation of a PPP because public and private agents share a common and broad objective: guarantying traceable and safe food in the supply chain.

To analyze these two cases, we first recall the emergence of those partnerships. Then, based on the characteristics of a PPP in a food safety context (Table 1), we present the mechanisms of incentives alignment between public and private interests, the information mechanisms, and the joined mechanisms of enforcement of those industry wide programmes. We also consider mechanisms to avoid free riding and reduce uncertainties surrounding transactions such as in contractual PPPs. This allows us to compare these two different PPPs and highlight their general and specific features.

For the Canadian case study, information was collected through interviews with the main actors of the system (the producers' union, traceability agency general director, representative of the beef producers), governmental reports, websites and related documentation. Most interviews have taken place between March and May 2015.

For the French case study information was gathered through interviews with public authorities in charge of food safety controls and importers operating in produce imports (importers, board of importers, and board of wholesalers). These interviews have started in 2004 and have taken place every year since then. There are three import markets in France: Perpignan, Rungis and Marseille that represent from 80 to $90 \%$ of French imports of fresh produce. Importers have supermarkets as main customer. Supermarkets sell $75 \%$ of the total volume of fresh produce (2014 
Kantar Worldpanel). ${ }^{12}$ It is worth noting that two programmes exist in the imports industry of fresh produce. One is implemented in the market of Perpignan (South of France) and the second is implemented in the market of Rungis (near Paris). In 2014, 58 importers have committed themselves to the "Démarche Qualité" issued on the Perpignan market, while 25 importers were part of the "Fel Partenariat", implemented in the Rungis market. Firms that operate in Rungis also operate in Marseille market, a large harbor close to the Mediterranean Sea. Since 2006, importers have been interviewed every two years. Owners and employees, are asked questions, faceto-face, about the firm situation, and particularly about characteristics such as total amount of sales, main produce, specialization, resources allocated to safety controls, and about their operating environment (procurement and suppliers, customers). Our questionnaire also included some questions about the firm's perception of the pressure exerted by public authorities and their main customer with respect to safety issues.

\subsection{PPP's for traceability in Canada}

\subsubsection{Emergence and purposes}

Traceability systems can be quite useful in the event of a food safety crisis, in getting or maintaining access to international markets, and in being able to trace back the origin of products for marketing. Their implementation is however often done by public authorities and do not necessarily take into account the needs and constraints of the industry. Hence, we often observe resistance to the introduction of such systems from the industry, the latter being more preoccupied by short-term costs and constraints than long-term benefits. Governments should therefore pay special attention to challenges that represent the implementation of a traceability system for the industry if they want to successfully achieve their objectives. In this kind of context, cooperation between private and public actors can overcome many of these challenges and rapidly lead to efficient traceability systems.

Agrifood actors and public authorities in the province of Quebec, Canada, have experienced this type of cooperation. The repeated occurrence of food health crisis in Europe in the 1990s ( $m a d$ cow disease, foot-and-mouth disease) has prompted the idea among public authorities and the main producers' union of creating a traceability system. At the end of the 1990s, they created a partnership in order to implement a permanent system of cattle identification and traceability from farms to fork for beef, sheep and deer. The Quebec beef industry represent only $4 \%$ of the national production but the veal production is about $83 \%$. In 2014 , there was 11,000 farms producing different kind of beef in this province but there were no slaughterhouses. ${ }^{13}$ The traceability system is defined by a regulation, the P-42, r.7 Bill. ${ }^{14}$ This traceability system goes beyond the one imposed by the federal government; in addition to the identification of animals, there is tracking of animal movements. For the system management purpose, an autonomous non-profit organization, Agri-traçabilité Québec (ATQ), was established in 2001. ATQ is managed by a board of directors consisting of governmental actors (the ministry of agriculture and the organization managing public agricultural insurance programmes (La Financière Agricole) and the producer union (Union des Producteurs Agricoles). A producer chairs the board. The main objective of this partnership is to efficiently align public regulations and the industry's constraints.

\footnotetext{
12 http://www.franceagrimer.fr/content/download/37755/347083/file/2014bilan\% 20achats\%20de $\% 20$ fruits $\% 20$ et $\% 201 \%$ C3\%A9gumes.pdf.

${ }^{13}$ http://www.bovin.qc.ca/fr/la-production/portrait-global/coup-doeil.php (February 2016).

${ }^{14}$ http://www2.publicationsduquebec.gouv.qc.ca/dynamicSearch/telecharge.php?type $=3 \&$ file $=/$ P_42/P42R7.HTM $($ May 2015) .
}

\subsubsection{Incentives alignment}

\section{Shared goals}

From an industry's interest point of view, the system first represented a tool to contain a potential sanitary crisis and a mean of adding value to agricultural products since the government wanted to put in place a complete system from farm to fork. That way, the system could improve the competitiveness of the Quebec agricultural sector by gaining or maintaining access to international markets (Lavoie and Forest, 2009). More specifically, the main incentives to participate in the implementation of a traceability system for producers are economical. The first incentive consists of the fact that a farm-to-fork system can potentially increase returns to Quebec producers in adding value to their products. The second incentive is that the ministry of agriculture committed to pay for the management of the whole system.

In its beginning, the system was fully subsidized by the ministry of agriculture. The first tags were given to producers and subsidies were provided to buy electronic tag readers. It is worth noting that ATQ, following a joint decision by the partnership, imposes only one supplier of tags in the whole province. According to our interviews, this choice has allowed to secure lower tags prices in Quebec compared to other provinces. The third incentive was to reduce economical losses following a sanitary crisis, although this incentive has become less obvious to producers over the years. Finally, another incentive emerged later with the development of herd management tools using the system's database. The traceability system could then allow the use of database information to obtain export certificates from the Canadian Food Inspection Agency (CFIA). Indeed, veterinarians from CFIA can use data from the database created by ATQ to issue their certificate. It must be noted, however, that the first and most important incentive, the possibility of adding value to products, has been greatly reduced in recent years, as the system of traceability from farm to fork remains incomplete. ${ }^{15}$

From a public interest point of view, the establishment of such a system would provide better food safety to consumers and address animal health concerns. Our interviews revealed that the government's objectives were more or less the same than those of producers. Both industry and government had converging interests in establishing an industry-wide traceability system. Moreover, a partnership would decrease the system's costs for both partners, as we shall see.

\section{Shared risks}

The cost of the system is shared between the provincial government and the producers. The government provides a budget to develop the system and run ATQ, while the producers have to purchase the identification tags (Lavoie and Forest, 2009). There is also a shared responsibility between partners: the government ensures public health; ATQ provides for technical support and dataset management; producers identify their animals with tags and provide information to ATQ.

\section{Reliability}

The reliability of the system rests upon the participation of the various actors of the system, their honesty in declaring their data (producers/slaughterhouses) and the effectiveness of ATQ.

\footnotetext{
15 The initial government willingness to stretch the traceability system into processing and distribution has not been translated into reality yet. It seems that the priorities of the following governments have changed; a complete traceability system from farm to fork is not possible without the government's support.
} 


\section{Accountability}

All agents involved in the system are specifically responsible for their task. Producers are responsible of declaring their animals, buy the tags and put them on their animals. Slaughterhouses and auctions are responsible for transmitting animals' data to ATQ. The ministry of agriculture is responsible for enforcing the system through controls and inspections. Finally, ATQ is responsible for managing data, bring technical support to producers and make the system work properly.

Since the traceability system does not go beyond slaughter, it is still easy to identify which agent has faulted in case of failure.

\subsubsection{Information}

Our interviews revealed that the fact that the traceability system was crafted within a partnership involving producers has made its implementation better adapted to the farm realities and faster than an implementation done exclusively by the government. The partnership allowed to: decrease information asymmetry, increase trust among partners, and reduce costs associated with information search. The Fédération des Producteurs de Bovins du Québec (FPBQ), the provincial cattle marketing board, has been a particularly pro-active partner at that level. It communicated a lot of information on the advantages, subsidies offered and logistics of the system to producers through their regional representatives network. The implementation was also made much easy by using the existing communication channels of the marketing board.

\subsubsection{Enforcement}

Since the government is responsible for the regulation on traceability, it ensures compliance and distributes fines to deviant producers through their inspectors. Also, the public agricultural insurance program uses ATQ's data to provide insurance coverage to producers. If animals are not properly identified, the producer's coverage might be inadequate. Finally, ATQ monitors data accuracy and detects any problems rapidly. It is continually looking for ways of simplifying producers' tasks. The enforcement of the system is largely based on the coercive powers of the State but it is worth noting that the cattle producers' organization provides information on the importance of maintaining the system, therefore reducing compliance cost at the producer level.

\subsection{PPP's for fresh produce in France}

\subsubsection{Emergence and purposes}

French importers negotiated with public authorities in 2001 to introduce voluntary safety programmes carrying out laboratory analyses to monitor the amounts of pesticide residues in fresh produce imported into the European Union. Those programmes, suggested by importers once negotiated, were then approved by the General Service for Consumption, Competition, and the Repression of Fraud (DGCCRF), the public authority in charge of enforcing the law and monitoring food safety in France. The first objective was to better monitor foreign products entering the French market in particular and the European markets at large.

\subsubsection{Incentives alignment}

\section{Shared goals}

In the French import industry, these safety agreements aimed at enabling the importers to collectively abide by their new obligations with regard to self-monitoring. For public authorities, it allows to increase the number of controls and to transfer cost of doing so to importers. Public authorities and importers work together in order to better monitor the safety of fresh fruit and veg- etables entering the French and the European markets. For importers, these self-monitoring safety agreements help them comply with their obligations to check the safety of fresh produce and to mutually share costs of controls.

\section{Shared risk}

Public Private Partnerships for food safety purpose are not common in France as in Europe. In that regard, public authorities gamble with their credibility in their objective to protect consumers from safety defects. Indeed, public authorities might face a big pressure from the social sphere if a safety defect occurs. Consumers and political actors are aware of this risk that media intensifies sometimes. For instance, in France, the horse's meat labeled as beef meat has received large media coverage leading to the implementation of food safety regulation schemes that avoid this type of failure. Since fresh produce is most of the time considered as generic by consumers (at least not recognized as branded product), the reputation of the whole industry is at stake (Rouvière and Soubeyran, 2011). The commercial threat, losing market shares, is a big issue for anonymous importers who sell anonymous products.

\section{Reliability}

Each participant agrees to record all their preventive actions and controls. Self-reporting allows for second level inspections where regulatory agencies evaluate a firm's compliance by monitoring its records.

\section{Accountability}

With regard to liability, if a safety defect occurs, it is the individual firm, the importer, which is liable under criminal law. These self-monitoring safety agreements are voluntary schemes and importers who are excluded can no longer benefit from the advantages provided by the agreement: (i) cost-sharing for the controls and (ii) reduction of resources required in implementing a common procedure. Regarding authorities, their controls have become second-level controls, that is, authorities rely on the recordkeeping of self-monitoring provided by the importers. At the same time, in the event of an anomaly, the authorities assume that the importers act in good faith. If the inspectors of the French Authorities in charge of monitoring and control believe that the resources mobilised by importers in the context of the safety self-monitoring are sufficient, the importer will not be held liable under criminal law.

\subsubsection{Information}

Importers benefit from an information program providing regular updates on regulations to keep them informed both at the European and national levels. Regulation information is centralized and then shared, free of charge, with importers. Moreover, the agreement provides a free mandatory training program for those in charge of quality. People in charge of quality must take some classes on quality, methods and risk management in order to implement the procedure of the agreement in the most appropriate way. Lastly, participating firms use a special logo on their bills. Importers can thereby signal that their produce is safer or better controlled, and indicate their commitment to safety to their customers. This logo is a business-to-business signal.

\subsubsection{Enforcement}

The PPP is organised around private enforcement and government oversight. In this context, joining the agreement can be perceived as a mean, for the importers, to reduce the scope of the 
controls of public norms within the group. It also allows them to reduce the extent of their own legal liability in the event of a safety issue. For individual firms, if inspectors of the DGCCRF believe that the effort provided is not enough, they can charge the firm. Prosecution ranges from fine to time in jail. Moreover, if an importer

doesn't provide enoygh effort it can be temporary or permanently

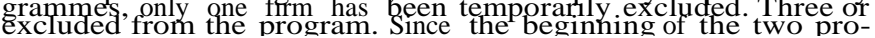

four have left the program by themselves due to bankruptcy.

Every year tne board or importers suomit a report to tne frencn authority that summarizes all the preventive actions importers have implemented during the year. The report provides information such as the total number of analyses and the total costs of
is worth noting that at each renewal, public authorities ask importers and their representatives to provide stronger proofs of the efficiency of the system and to enhance the whole system. For the renewal to be complete, importers must comply with those new requirements.

\subsection{Discussion on the case studies}

In this article, we were interested in the mechanisms at work in public-private collaborations for food safety and traceability. Our theoretical framework highlights all main characteristics of public-private partnerships for food safety. These characteristics have not yet been taken into account in the literature. In our case studies, we aimed to emphasize what are the main characteristics at work in the field that sustain the resilience of these types of programmes in two different sectors (fresh meat and fresh fruit and vegetable) and two different institutional environments (France and Canada). From these two case studies, we establish that PPPS for food safety and traceability have general features that are not linked to the environment in which they are implemented. In other words, some of their characteristics are not dependant of their institutional environment.

Table 2 gives a comparison between the two programmes implemented in Quebec and France. Both PPPs manage to align their incentives. They display shared goals, shared risks and accountability mechanisms. However, reliability rest upon industry's actors self-reporting in both cases. As for information, both PPPs use the industry informational advantage to reduce costs, use B2B communication channels and have record-keeping organisations. However, there isn't any recognition of the system's costs from the market, customers and consumers. Systems are costly but firms do not get any price premium.

The main difference between the two PPPs is their enforcement mechanism. Both PPP differ on their participation mode: mandatory in Canada and voluntary in France. In Canada, the producers' organization tries to enforce the PPP through information on the advantages of a traceability system but fines can be imposed by the ministry of agriculture if needed. In France, the PPP is not fully enforced since the credibility of the threat of being excluded from the program is very weak (Codron et al., 2007).

In the Canadian case, it seems that the mandatory participation gives resilience to a program involving roughly 11,000 producers. If the participation were voluntary, costs supported might have been too high for producers to stay in the program. Our case studies indeed reveal that these arrangements must operate at the lowest cost possible to keep the industry partners in. On the other hand, a mandatory program solely implemented by public authorities would have been very costly for the latter. It has been mentioned during interviews that producers would certainly not have paid for the management of the whole system and a financial partnership with the government was essential. This is in line with the

Table 2

Results from our case studies.

Participation

Traceability system in

Québec

Mandatory

resh produce in

France

Voluntary

\begin{tabular}{|c|c|c|}
\hline \multicolumn{3}{|l|}{ Incentives alignment } \\
\hline Shared goals & $\mathbf{U}$ & $\mathbf{U}$ \\
\hline Shared risks & $\mathbf{U}$ & $\mathbf{U}$ \\
\hline Reliability & Not fully & Not fully \\
\hline Accountability & $\mathbf{U}$ & $\mathbf{U}$ \\
\hline \multicolumn{3}{|l|}{ Information } \\
\hline $\begin{array}{l}\text { Private information } \\
\text { disclosure }\end{array}$ & $\mathbf{U}$ & $\mathbf{U}$ \\
\hline $\begin{array}{l}\text { Regord-keeping system } \\
\text { Industrys }\end{array}$ & $\mathrm{U}_{\text {Full (fines) }}$ & U Not fully enforced \\
\hline
\end{tabular}

argument provided by van der Voort (2015) who analysed a program of quality control of eggs in the Netherlands that constitutes an example of coregulatory failure.

In Canada and in France, our interviews revealed that many producers consider this system more efficient than other systems in the world. The implementation of these systems notably allowed creating a sanitary/safety crisis plan that is complete and functional.

In Canada, it is considered as a success story both nationally and abroad (Lavoie and Forest, 2009). The expertise developed is internationally recognized and is exported in South America and other Canadian provinces. It allowed the province to be more competitive in export markets such as Japan for instance (ATQ, 2010). However, the number of agents involved in the system and its ambitious objective has of course a few inconvenient. Firstly, producers have complained about the costs and management of the tags that might fall off during the animals' life. Very good material is necessary to obtain and maintain producers' participation. Secondly, producers' enthusiasm has faded away in recent years, as the government did not extend traceability to the whole chain, probably due to the complexity of the task and the individual initiatives already in place among some distributors. Tracing an animal (non-processed) is an easier task than tracing a piece of meat, especially when this piece of meat is composed of many animals such as the case for grounded meat. Traceability from slaughterhouses to consumers is logistically more complex, costlier and requires new business practices compared to live animal traceability. There are also many traceability initiatives already in place among distributors and restaurant chains. These enterprises do not see the advantage of implementing another/different traceability system and are therefore not willing to participate in the industry-wide system. Furthermore, our interviews revealed that government' interests and priorities have changed over the years as new governments have been elected since the establishment of the system. Investing in a complete farm-to-fork traceability system would not be seen as important as it was fifteen years ago. The incomplete traceability system has much reduced producers' incentive to participate in the system. Our interviews revealed that producers have the impression that the system is becoming too much binding for very few advantages.

In France, the recognition of the program and the renewal by public authorities since 2001 suggests that they are satisfied with the outcomes. In the Rungis market, since 2009, the "Fel Partenariat" has been opened to the wholesale activity and to exporters operating in the Rungis market that represented 50 firms in 2014. This extension to other food operators means that the program is credible for other food operators than importers. It also means that these programmes might need a critical size to be 
recognized in the whole supply chain. Recognition in B2B relationships is still a problem for participating firms. They bear a cost but they don't get any price premium on the market. Moreover, in its current organizational structure, the program poses a problem in terms of incentives. The participation is voluntary but the program lacks strong private enforcement. Current resilience of the program comes from a low level of enforcement. This latter point could explain why the French program has been extended to other activities while it is not the case in Canada. On both markets, some importers (not a lot) do not enter the program. This leads to an equity issue related to the regulation enforcement between participating and non-participating importers. Second, implementing the program is based on the fact that the public authorities' agents must ensure that the importer board carries out its control and enforcement functions. In others words, to be fully operational, PPPs should have prescribed contingency on the importer board. They should have been accountable if one of their members failed to provide the right effort. In that sense, the importer board must display sufficient incentives to make the collective discipline mechanisms effective within the group. This task is not easy because of a potential conflict of interest knowing that importers pay the importer board. One way to avoid this failure could have been to create a third party, a certifier that audits importers for instance. However, a third-party certification would certainly increase the costs of the program, decrease flexibility and could lead importers to exit the program.

\section{Concluding remarks}

Food safety and traceability are important issues for food operators and public authorities. Both agents need to prevent themselves from the occurrence of an outbreak or loss of consumers' confidence. This is particularly true for products that consumers consider as generic (unbranded products) like seafood, fresh meat and fresh produce. And they must do so with industry-wide systems that implies public good issues and adaptive incentive schemes. For this type of food items, economic agents face high transaction costs in searching safe food and in identifying bad or good producers. While collaborative arrangements between public authorities and the food industry are increasingly used to provide food safety, their nature, advantages and limits have been barely analysed in the literature. In this article, we argued that these arrangements show characteristics of PPPs and we provided a new analytical framework that allows us to take into account their industry-wide dimension, therefore avoiding the reference to a regulatory or political process that would sustain their emergence.

We applied our framework to two case studies in France and in Canada that differ in their institutional environments and products concerned. From those case studies, we observed that the two PPPs align their incentives, notably through shared goals, shared risks and accountability mechanisms. Our analysis also revealed that enforcement mechanisms are an important feature and that further research should deepen this point. Our cases presented an interesting trade-off for public authorities and firms between costs, level of enforcement and participation.

These PPPs, although resilient and seemingly efficient, remain however fragile. Some situations may undermine the partners' common vision such as a change in one of the partners' priorities. We have also observed that these organisations must be very adaptive and fit as much as possible agrifood operator's process of operations to keep the program low cost and attractive. Otherwise, private partners lose their interest in participating. Finally, we can also mention that these arrangements, once in place, modify agents' behaviour and change their individual trade-off, which may threaten the resilience of such programmes.

\section{References}

Antle, J.M., 1996. Efficient food safety regulations in the food manufacturing sector. Am. J. Agr. Econ. 78, 1242-1247.

ATQ, 2010. Saviez-vous qu'Agri-Traçabilité Québec est certifiée ISO 9001-2008 depuis mars2009? <http://www.agrireseau.qc.ca/bovinsboucherie/documents/ FeuilletTracabilite2010_basseResolution.pdf $>$.

Barzel, Y., 1982. Measurement cost and the organization of markets. J. Law Econ. 25 (1), 27-48.

de Bettignies, J.-E., Ross, T.W., 2004. The economics of public-private partnerships. Can. Public Policy 30 (2), 135-154.

Black, J., 2001. Decentring regulation: understanding the role of regulation and selfregulation in a'Post-Regulatory'World. Curr. Legal Probl. 54 (1), 103.

Boase, J.P., 2000. Beyond government? The appeal of public-private partnerships. Can. Pub. Administration 43 (1), 75-92.

Busch, L., Bain, C., 2004. New! improved? The transformation of the global agrifood system. Rural Sociol. 69 (3), 321-346.

Cafaggi, F., 2010. Private regulation, supply chain and contractual networks: the case of food safety. UI Working Papers RSCAS 2010/10.

Codron, J.-M., Fares, M., Rouvière, E., 2007. From public to private regulation? The case of negotiated agreements of French import industry of fresh produce. Int. J. Agric. Resour. Gov. Ecol. 6 (3), 415-427.

Coglianese, C., Mendelson, E., 2010. Meta-regulation and self-regulation. Regulation, $12-11$.

Forge, F., Fréchette, J.-D., 2005. Mad cow disease and Canada's cattle Industry. Library of Parliament, Parliamentary Information and Research Service. <http:// www.parl.gc.ca/Content/LOP/researchpublications/prb0301-e. htm\#consequencestxt > (April 2014).

Garcia-Martinez, M., Fearne, A., Caswell, J., Henson, S., 2007. Co-regulation as a possible model for food safety governance: opportunities for public-private partnerships. Food Policy 32 (3), 299-314.

Garcia-Martinez, M., Verbruggen, P., Fearne, A., 2013. Risk base approaches to food safety regulation: what role for co-regulation? J. Risk Res. 16 (9), 1-21.

Golan, E., Krissof, B., Kuchler, F., Calvin, L., Nelson, K., Price, G., 2004. Traceability in the U.S. Food Supply: Economic Theory and Industries Studies. Agricultural Economic Report No. 830, USDA/ERS.

Hennessy, D.A., Roosen, J., Jensen, H.H., 2003. Systemic failure in the provision of safe food. Food Policy 28 (1), 77-96.

Hobbs, J.E., 2004. Information asymmetry and the role of traceability systems. Agribusiness 20 (4), 397-415.

Hobbs, J.E., Kerr, W.A., 1992. Costs of monitoring food safety and vertical coordination in agribusiness: what can be learned from the British Food Safety Act 1990? Agribusiness 8 (6), 575

Hobbs, J.E., Kerr, W.A., Yeung, M.T., 2007. Identification and Analysis of the Current and Potential Benefits of a National Livestock Traceability System in Canada. Agriculture and Agri-Food Canada. Cat No. A34-9/2007E-PDF. 50p.

Hodge, G.A., Greve, C., 2007. Public-Private Partnerships: An international Performance Review. Essays on Service Delivery and Privatization. Public Administration Review, May/June.

Iossa, E., Martimort, D., 2015. The simple microeconomics of public-private partnerships. J. Pub. Econ. Theor. 17 (1), 4-48.

Kersting, S., Wollni, M., 2012. New institutional arrangements and standard adoption: evidence from small-scale fruit and vegetable farmers in Thailand. Food Policy 37 (4), 452-462.

Lavoie, G., Forest, J.-F., 2009. Implementation of a traceability system from constraints to opportunities for the industry: a case study of Quebec, Canada. Int. Food Agribus. Manage. Rev. 12 (2), 71-80.

McEachern, M.G., Warnaby, G., 2004. Retail 'Quality Assurance' labels as a strategic marketing communication mechanism for fresh meat. Int. Rev. Retail Distrib. Consumer Res. 14 (2), 255-271.

Mayer, F., Gereffi, G., 2010. Regulation and economic globalization: prospects and limits of private governance. Bus. Politics 12 (3).

Ménard, C., 2014. Embedding organizational arrangements: towards a general model. J. Inst. Econ. 10 (04), 567-589.

Newell, D.G., Koopmans, M., Verhoef, L., Duizer, E., Aidara-Kane, A., Sprong, H., et al., 2010. Food-borne diseases - the challenges of 20 years ago still persist while new ones continue to emerge. Int. J. Food Microbiol. 139, S3-S15.

Narrod, C., Roy, D., Okello, J., Avendaño, B., Rich, K., Thorat, A., 2009. Public-private partnerships and collective action in high value fruit and vegetable supply chains. Food Policy 34 (1), 8-15.

North, D.C., 1994. The historical evolution of polities. Int. Rev. Law Econ. 14 (4), 381-391.

Ogus, A., 2000. Self-regulation. Encyclopedia Law Econ. 5, 587-602.

Oosterveer, P., 2015. Special issue on the patterns of interplay between public and private food regulation: sustainable food governance by governments and markets. Eur. J. Risk Regul. 6 (4), 525-531.

Pouliot, S., 2011. The FDA Food Safety and Modernization Act and the Exemption for Small Firms. In: Annual Meeting of the Agricultural and Applied Economics Association, July, pp. 24-26.

Posner, R.A., 1973. Economic Analysis of Law. Little Brown and Company.

Rouvière, E., Caswell, J.A., 2012. From punishment to prevention: a French case study of the introduction of co-regulation in enforcing food safety. Food Policy 37, 246-254.

Rouvière, E., Soubeyran, R., 2011. Competition vs. quality in an industry with imperfect traceability. Econ. Bull. $31 \quad$ (4), 3052-3067. 
Rouvière, E., Soubeyran, R., Bignebat, C., 2010. Heterogenous effort in voluntary programmes on food safety: theory and evidence from the French import industry of fresh produce. Eur. Rev. Agric. Econ. 37 (4), 479-499.

Rouvière, E., 2016. Small is beautiful: firm size, prevention and food safety. Food Policy 63, 12-22.

Royer, A., Ménard, C., Gouin, D.M., 2016. Reassessing marketing boards as hybrid arrangements: evidence from Canadian experiences. Agric. Econ. 47 (1), 105116.

Sinclair, D., 1997. Self-regulation versus command and control? Beyond false dichotomies. Law Policy 19, 529-559.

Tauxe, R.V., 1997. Emerging foodborne diseases: an evolving public health challenge. Emerg. Infect. Dis. 3 (4), 425-434.

Verbruggen, P., Havinga, T., 2014. The rise of transnational private meta-regulators. Osgoode Legal Studies Research Paper, 71.

Verbruggen, P., Havinga, T., 2015a. Special issue on the patterns of interplay between public and private food regulation. Eur. J. Regul. 6 (4), 482-487
(Introduction to the Special Issue on the Patterns of Interplay between Public and Private Food Regulation).

Verbruggen, P., Havinga, T., 2015b. Special issue on the patterns of interplay between public and private food regulation. Food Saf. Meta-Controls Neth. Eur. J. Risk Regul. 6 (4), 512-524.

van der Voort, H., 2015. Special issue on the patterns of interplay between public and private food regulation. Co-Regul. Failure Food Ind. Eur. J. Risk Regul. 6 (4), 502-511.

\section{Websites}

CFIA, 2014. <http://www.inspection.gc.ca/about-the-cfia/accountability/ inspection-modernization/case-for-change/eng/1337194116466/ 1337194257540>. 